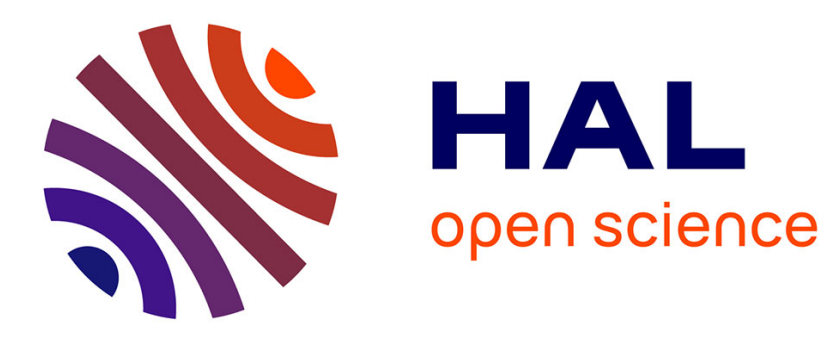

\title{
POLAR: a compact detector for GRB polarization measurements
}

\author{
J.P. Vialle, F. Barao, C. Casella, K. Deiters, S. Deluit, C. Leluc, A. \\ Mchedlishvili, M. Pohl, N. Produit, D. Rapin, et al.
}

\section{- To cite this version:}

J.P. Vialle, F. Barao, C. Casella, K. Deiters, S. Deluit, et al.. POLAR: a compact detector for GRB polarization measurements. R. Battiston, T. Li and P. Zuccon. Third International Conference on Particle and Fundamental Physics in Space (SpacePart '06), Apr 2006, Beijing, China. Elsevier, 166, pp.273-275, 2007, 10.1016/j.nuclphysbps.2006.12.025 . in2p3-00116722

\section{HAL Id: in2p3-00116722 \\ https://hal.in2p3.fr/in2p3-00116722}

Submitted on 27 Nov 2006

HAL is a multi-disciplinary open access archive for the deposit and dissemination of scientific research documents, whether they are published or not. The documents may come from teaching and research institutions in France or abroad, or from public or private research centers.
L'archive ouverte pluridisciplinaire HAL, est destinée au dépôt et à la diffusion de documents scientifiques de niveau recherche, publiés ou non, émanant des établissements d'enseignement et de recherche français ou étrangers, des laboratoires publics ou privés. 


\title{
POLAR: A compact detector for GRB polarization measurements
}

\author{
J.P. Vialle ${ }^{\text {a }}$, F. Barao ${ }^{\text {b }}$, C. Casella ${ }^{\text {c }}$, K. Deiters ${ }^{\text {d }}$, S. Deluit ${ }^{\text {e }}$, C. Leluc ${ }^{\text {c }}$, A. Mchedlishvili ${ }^{d}$, M. Pohl \\ ${ }^{c}$, N. Produit ${ }^{\text {e }}$, D. Rapin ${ }^{c}$, E. Suarez-Garcia ${ }^{d}$, Ch. Tao ${ }^{f}$, R. Walter ${ }^{\text {e }}$, C. Wigger ${ }^{d}$, A. Zehnder ${ }^{d}$ \\ ${ }^{\mathrm{a}} \mathrm{LAPP} / \mathrm{IN} 2 \mathrm{P} 3 / \mathrm{CNRS}$, Annecy, France \\ ${ }^{\mathrm{b}}$ LIP, Lisboa, Portugal \\ ${ }^{\mathrm{c}} \mathrm{DPNC}$, Université de Genève, Switzerland \\ ${ }^{\mathrm{d}}$ PSI, Villigen, Swizerland \\ eUniversité de Genève, Switzerland \\ ${ }^{\mathrm{f}} \mathrm{CPPM}$, Université de la Méditerrannée, France
}

Though polarization measurements of X-rays can provide essential information for identifying processes responsible of their emission by astrophysical objects, almost no experimental data exist yet. We propose here a novel wide field compact detector for hard X-ray polarization measurements based on Compton scattering process and made of low-Z fast scintillators.

\section{INTRODUCTION}

Despite of significant progress in theories and experimental studies the 35 years old GRB phenomena still remains a challenge. Main problems are related with the genuine character of the GRB progenitors and mechanisms responsible for release of energy and production of relativistic outflows. Photon polarization is one of the main parameters which could allow a clear distinction between different theoretical models in order to fully understand the GRB nature. To date however, despite of several attempts, polarization data from Gamma Ray Bursts are very rare and in general jeopardized by large errors. In addition to the experimental difficulty to measure polarization, transient sources like GRBs require that the detector has a large acceptance, covering a wide region of the sky, in order to provide a statistically significant sample of polarization measurements. For this purpose we propose POLAR, a GRB polarimeter exploiting Compton scattering and well known detection technologies $[1]$.

\section{THE POLAR DETECTOR}

POLAR is designed to determine the polarization of photons in the energy range from tens of $\mathrm{KeV}$ to several $\mathrm{MeV}$ which cover well the peak energy flux of the prompt GRB emission. It is based on large angle Compton scattering which has a strong modulation pattern in the azimuth angle around the photon polarization direction [3]. POLAR is a simple and homogeneous detector made of low $\mathrm{Z}$ sensitive material for which the Compton cross-section dominates over the photoelectric effect in the above energy range. Each bar of detector plays the double role of scatterer and of absorber. Observing the recoil electron from large angle Compton scattering together with subsequent photon absorption (photoelectric effect) or scattering (Compton) enables to reconstruct the polarization direction. Small angle Compton scattering gives very little energy deposition and let the polarization direction almost unchanged, thus practically not affecting the measurement. Monte Carlo simulations confirmed the strong correlation between the photon polarization direction and the modulation pat- 
tern observed by analysis of two most energetic energy depositions.

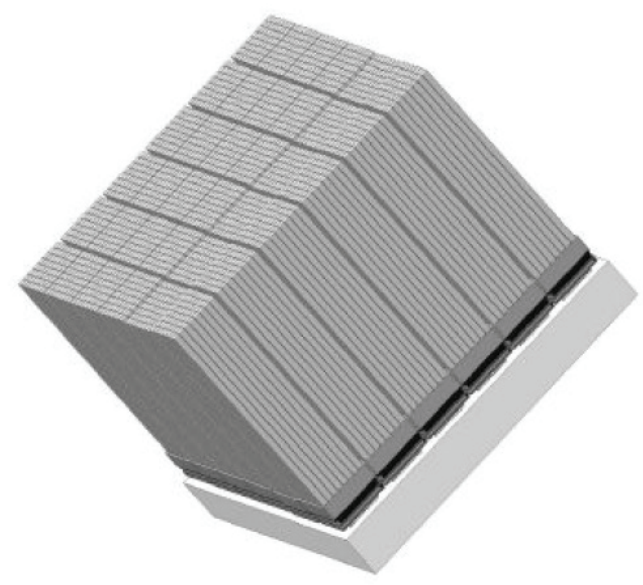

Figure 1. Schematic view of the detector scintillator array and photomultiplier on the right side

The prototype design of the POLAR detector consists of an array of 2304 scintillation bars with dimensions of $4 \times 4 \times 200 \mathrm{~mm} 3$ each, giving overall dimensions of the active volume of $192 \times 192 \times 200$ $\mathrm{mm} 3$. The single bar segmentation was selected to fit with typical ranges of recoil electrons and match the anode area of the multi-anode photomultipliers (MAPM) like H6568 from Hamamatsu. These MAPMs are characterized not only by very high gain and light quantum efficiency but also have been already used in space. The front and side shielding consists of a $1 \mathrm{~mm}$ thick carbon fiber. Its role is to absorb low energy photons and charged particles as well as to provide a stable mechanical enclosure. There is no active shielding planned though for this purpose one can consider to use outer layers of the plastic array itself. The lower part of the scintillator array is coupled to the MAPMs below which the associated front-end electronics and power distribution are located. These elements also provide additional passive underneath. A schematic view of the POLAR detector is shown in Fig. 1.

\section{MONTE-CARLO SIMULATION}

The properties and response of the instrument were simulated using the package GEANT4 from CERN. The full geometry of the detector was described, and the photo-multipliers and their electronics were approximated by a uniform block of aluminum-like material of $10 \mathrm{~cm}$ thickness with density reduced to $0.9 \mathrm{~g} / \mathrm{cm}^{3}$. Photons were generated in the $10 \mathrm{keV}-600 \mathrm{keV}$ energy range with a polarization plane parallel to one of the detector side wall. Events were accepted if there was at least 2 energy depositions above a threshold of $5 \mathrm{keV}$. For an energy spectrum of Band type [2] with parameters $\alpha=-1, \beta=-2.5$, and $\mathrm{E}_{p} e a k=$ $200 \mathrm{keV}$, it was found that $14 \%$ of the events fulfill the above double energy deposition coincidence. Background from high energy cosmic rays is easily removed by an upper threshold at 300 $\mathrm{keV}$ on the total energy deposited in the detector with only little effect on the GRB photon detection efficiency. At lower energies, particles are stopped by the $1 \mathrm{~mm}$ thick carbon shield wrapping the detector. Fig. 2 shows the modulation

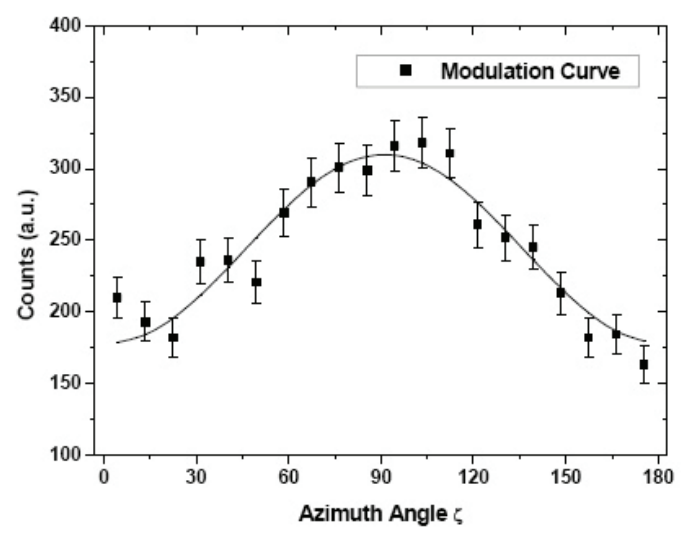

Figure 2. Modulation curve with a cosine function fit for the Band spectrum of photons. The polarization direction was at $\zeta=0$

curve seen by the detector for $100 \%$ polariza- 
tion of incoming photon. This curve well represented by the cosine function has a minimum in the direction of the polarization and a relative difference between the max and the min (so-called modulation factor) greater than $30 \%$. This factor has only a $20 \%$ variation in the energy range $100-$ $600 \mathrm{keV}$ as shown in fig. 3, and its average value decreases only from 0.32 to 0.22 for polar angle of the impinging photons from $0^{0}$ to $70^{\circ}$. The ef-

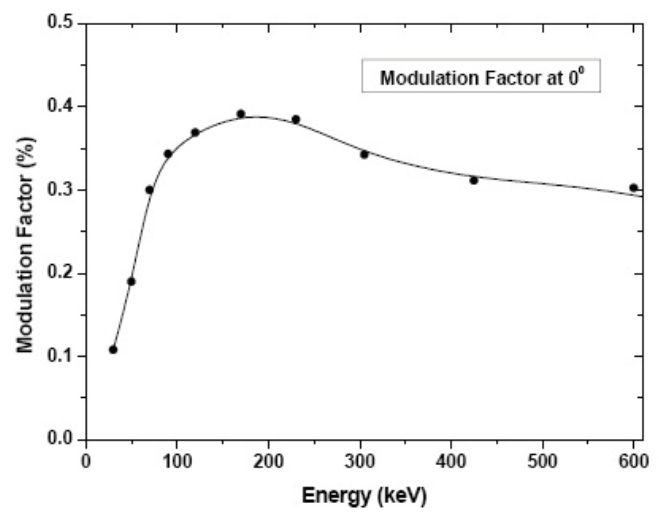

Figure 3. Detector modulation factor as a function of the photon entrance angle for X-rays with Band energy spectrum

fective area of POLAR, defined as the product of the photon detection probability by its geometrical surface is fairly constant around $200 \mathrm{~cm}^{2}$ for photon energy in the range $100 \mathrm{keV}-600 \mathrm{keV}$, and falls rapidly to 0 at lower energy. This effective area is also roughly constant for polar angles of photons up to $50^{\circ}$ and then decreases by a factor of about 2 at $70^{\circ}$. Taking these results into account, the effective detector field of view should cover about $1.3 \pi$ srad.

\section{GRB DETECTION AND POLARIZA- TION MEASUREMENT}

With the above characteristics, the POLAR detector would allow to detect at $3 \sigma$ level polariza- tion as low as $15 \%$ for GRB with a total energy fluence between 10 and $300 \mathrm{keV}$ equal to $10^{-5} \mathrm{erg} / \mathrm{cm}^{2}$. Fig 4 shows the sensitivity with a level of background around 500 events/sec.

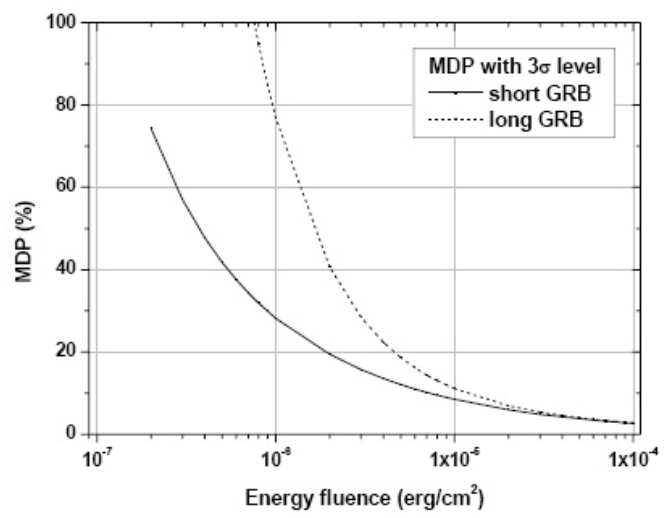

Figure 4. minimum detectable polarization as a function of the total energy fluence of the GRB source

\section{CONCLUSION}

The design of POLAR is optimize to measure polarization from GRB's and other strong transient sources, and is characterized by a wide field of view, which should allow to measure accurately the polarization degree for several GRB per month. Tests in a beam of polarized photons at PSI are underway and the first results are very promising. They will allow to confirm all these numbers and to optimize the design of the detector.

\section{REFERENCES}

1. Produit N. et al., NIM, A550, 616, 2005

2. D. Band et al., ApJ 413, 281-292, 1993

3. Soffita P. et al., NIM, A510, 170, 2003 